\title{
The functions of the cytoskeleton and associated proteins during mitosis and cytokinesis in plant cells
}

\author{
Shanwei Li, Tiantian Sun and Haiyun Ren* \\ Key Laboratory of Cell Proliferation and Regulation Biology of Ministry of Education, College of Life Science, Beijing Normal \\ University, Beijing, China
}

\section{OPEN ACCESS}

Edited by:

Fatima Crrckova,

Charles University in Prague,

Czech Republic

Reviewed by:

Sabine Müller,

University of Tuebingen, Germany

Clément Thomas,

Public Research Centre for Health,

Luxembourg

*Correspondence:

Haiyun Ren,

Key Laboratory of Cell Proliferation and Regulation Biology of Ministry of Education, College of Life Science,

Beijing Normal University, No.19, Xin JieKouWai Street, Beijing 100875,

China

hren@bnu.edu.cn

Specialty section:

This article was submitted to

Plant Cell Biology,

a section of the journal

Frontiers in Plant Science

Received: 01 February 2015 Accepted: 08 April 2015

Published: 27 April 2015

Citation:

Li S, Sun T and Ren H (2015)

The functions of the cytoskeleton and associated proteins during mitosis and cytokinesis in plant cells.

Front. Plant Sci. 6:282.

doi: 10.3389/fp/s.2015.00282
In higher plants, microtubule (MT)-based, and actin filament (AF)-based structures play important roles in mitosis and cytokinesis. Besides the mitotic spindle, the evolution of a band comprising cortical MTs and AFs, namely, the preprophase band (PPB), is evident in plant cells. This band forecasts a specific division plane before the initiation of mitosis. During cytokinesis, another plant-specific cytoskeletal structure called the phragmoplast guides vesicles in the creation of a new cell wall. In addition, a number of cytoskeletonassociated proteins are reportedly involved in the formation and function of the PPB, mitotic spindle, and phragmoplast. This review summarizes current knowledge on the cytoskeleton-associated proteins that mediate the cytoskeletal arrays during mitosis and cytokinesis in plant cells and discusses the interaction between MTs and AFs involved in mitosis and cytokinesis.

Keywords: cytoskeleton, preprophase band, spindle, phragmoplast, mitosis, cytokinesis, plant

\section{Introduction}

In plants, microtubules (MTs) and actin filaments (AFs) are essential components of the basic machineries required for cell division and expansion. Unlike animal cells, plant cells are enfolded in pecto-cellulosic cell walls and do not migrate. Therefore, orientation of the cell division plane is crucial for the cellular organization of plant tissues. The MTs and AFs are involved in the selection of the division plane in preprophase cells and in the formation of the cell plate during cytokinesis (Muller et al., 2009; Liu et al., 2011b; Rasmussen et al., 2013).

The preprophase band (PPB) is a transient ring of cortical MTs and AFs specific to plant cells; PPB delineates the plane of cell division at the onset of mitosis and plays an essential role in division plane specification (Mineyuki, 1999). The PPB appears in the cell cortex in late G2 phase and persists throughout prophase, but disassembles with the breakdown of the nuclear envelope when the mitotic spindle forms (Dixit and Cyr, 2002). Mitotic spindle is a bipolar array of MTs that segregates chromosomes between daughter cells during mitosis. Moreover, an AF cage surrounds the spindle and maintains spindle position during mitosis (Lloyd and Traas, 1988; Katsuta et al., 1990). During cytokinesis, the formation of a new cell plate is accomplished by a dynamic AF- and MTbased structure known as the phragmoplast. The phragmoplast assembles at the center of the cell and grows centrifugally toward the parental cell wall. When the phragmoplast reaches the cortical site formerly marked by the PPB, the cell plate, and parental membranes fuse, thereby completing cytokinesis (Smith, 2001; Van Damme et al., 2007).

Both MT and AF structures play essential roles in cell division because the cell plate does not form in the absence of MTs (Clayton and Lloyd, 1985; Kakimoto and Shibaoka, 1987), and the 
treatment with actin polymerization inhibitors results in oblique cell plate formation (Hoshino et al., 2003; Sano et al., 2005). Moreover, interactions and cross-talk between MTs and AFs are involved in plant cell division (Wasteneys and Galway, 2003). In this review, we summarize the current findings on the cytoskeleton-associated proteins that mediate the cytoskeletal arrays during mitosis and cytokinesis in plant cells and focus on the MT and AF interactions involved in mitosis and cytokinesis.

\section{PPB Formation}

The PPB is a temporal structure that forms before mitosis. Although some plant species and cell types can divide in the absence of PPBs, e.g., starchy endosperm, meiocytes, and some cultured suspension cells (Otegui and Staehelin, 2000; Chan et al., 2005; Sabelli and Larkins, 2009), pharmacological or genetic disruption of PPBs can cause divisions in aberrant orientations in plant cells that can form PPBs normally (Vanstraelen et al., 2006). These observations suggest that PPB plays a key role in determination of the division plane.

A variety of MT-associated proteins (MAPs) have been identified to participate in PPB formation. Arabidopsis MT organization 1 (MOR1), a plant homolog of animal XMAP215, can accelerate both the growth and shrinkage rates of MTs in vitro and in vivo (Brouhard et al., 2008; Kawamura and Wasteneys, 2008). The MOR1 localizes to PPBs and other MT arrays (Kawamura et al., 2006). In the case of Arabidopsis thaliana mor1 mutant, nearly one-half of the dividing cells failed to form PPB before spindle formation and those that formed PPB were often disrupted (Kawamura et al., 2006). Tobacco MT-binding protein 200 (TMBP200), a homolog of MOR1, is also found on PPB (Hamada et al., 2004). Arabidopsis CLIP-associated protein (CLASP), which shares structural similarity with the XMAP215 family of proteins in animals, is implicated in PPB formation (Mimori-Kiyosue et al., 2005). In clasp mutants, PPB tends to be disoriented, and $\mathrm{PPB}$ narrowing is retarded compared with wild-type plants (Ambrose et al., 2007). The SABRE protein, which shares similarity with proteins of unknown function in eukaryotes, plays important roles in orientation of cell division and planar polarity. Moreover, Arabidopsis SABRE has recently been reported to stabilize the orientation of CLASP-labeled MT in the PPB, which is essential for cell division plane orientation (Pietra et al., 2013). MAP65 is an MT-binding protein family that is involved in PPB formation. MAP65s bundle MTs by forming cross bridges between overlapping MTs, thereby potentially contributing to the stability of PPB MTs via bundling (Smertenko et al., 2004). Katanin is an evolutionarily conserved protein complex for severing MT. In certain root cells of the lue1 mutant, early PPBs are disorganized and are sustained longer in the prophase stage than wild-type PPBs (Panteris et al., 2011).

Although plant cells lack centrosomes, plant proteins with similarity to the human centrosomal proteins are required for PPB formation. In A. thaliana, the TONNEAU1 (TON1) proteins related to the human centrosomal proteins FOP co-localize with PPBs. The ton 1 mutants are unable to form a PPB in $A$. thaliana (Azimzadeh et al., 2008). TON1 Recruiting Motif proteins (TRMs) have been recently shown to interact with TON1 in Arabidopsis. One of TRMs (TRM1) is found to bind and recruit TON1 to the cortical MTs (Drevensek et al., 2012). Recently, it has been reported that the activity of a regulatory complex composed of TON1, TRM, and a putative protein phosphatase 2A (PP2A) holoenzyme (TTP) is required for PPB formation and spatial control of cell division. All members of the TTP complex share similarity with animal centrosomal proteins, revealing an evolutionary link between MT organizing mechanisms in plant and other eukaryotes (Spinner et al., 2013).

The actin PPB is considered to be wider than the MT PPB (Palevitz, 1987). The formation of actin PPB depends on MTs because application of MT-depolymerizing drugs prevents formation of both the MT and actin components of the PPB (Palevitz, 1987; Vanstraelen et al., 2006). The actin PPB can also affect the MT PPB because actin depolymerization results in dramatic broadening of the MT PPB and shifting of division planes in dividing cells during the preprophase and prophase stages (Mineyuki and Palevitz, 1990). Thus, AFs and MTs may play indispensable roles in PPB in a coordinated manner. Until recently, some proteins were reported to regulate the cooperation or interaction between AFs and MTs in PPB. Arabidopsis formin 14 (AFH14), a type II formin, is found on the PPB and directly binds and bundles AFs and MTs in vitro (Li et al., 2010). Moreover, in the presence of both MTs and AFs, AFH14 has higher affinity to MT and preferentially binds to MTs; however, the presence of excessive AFH14 promotes cross-linkages of MTs and AFs (Li et al., 2010). AtKinG, a kinesin 14-type molecular motor from Arabidopsis, localizes to MTs and AFs by fluorescence double-labeling; AtKinG strongly labels the PPB in time-lapse cell division studies (Buschmann et al., 2011). NtKCH, a KCH homolog from tobacco BY-2 cells, is suspected to act as an MTAF cross-linker. In dividing cells, NtKCH accumulates in the PPB (Klotz and Nick, 2012). These results show that different kinds of proteins mediate MTs, AFs, or both MTs and AFs in the PPB, thereby indicating a variety of interactions between AFs and MTs, which participate in PPB formation.

\section{Spindle Formation and Position}

Unlike in animal cells, the mitotic spindle in plant cells originates from the nuclear envelope in prophase (De Mey et al., 1982; Ambrose and Cyr, 2008). Spindle assembly starts prior to PPB breakdown at prometaphase, with the spindle axis perpendicular to the plane of the PPB (Chan et al., 2005; Yoneda et al., 2005). Previous studies have demonstrated that $\mathrm{PPB}$ plays a role in the timely formation of a normal bipolar spindle (Ambrose and Cyr, 2008).

Similar to PPB, a number of MAPs have also been shown to participate in spindle formation. Apart from PPB, MOR1/TMBP200, CLASP, and MAP65 are implicated in spindle formation (Kawamura et al., 2006; Ambrose et al., 2007; Fache et al., 2010; Yasuhara and Oe, 2011). Kinesins have been implicated in spindle organization. A. thaliana kinesin-related 
protein 125c (AtKRP125c), a member of the plus end kinesin5 group, plays a role in establishing the spindle structure and cross-linking antiparallel MTs at the midzone (Wiedemeier et al., 2002; Bannigan et al., 2007). $\gamma$-Tubulin is distributed throughout the mitotic spindle and plays an indispensable role in the assembly of the bipolar spindle (Binarova et al., 2006; Pastuglia et al., 2006). A. thaliana NEDD1, which acts as an anchoring factor of $\gamma$-tubulin complex, decorates spindle MTs preferentially toward theirs minus ends. In nedd 1 mutants, nearly half of the dividing microspores show aberrant MT organization and abnormal spindles, thereby demonstrating the important role of NEDD1 in spindle formation (Zeng et al., 2009). Additionally, repressed $\gamma$-tubulin Complex Protein 4 (GCP4) expression by an artificial microRNA results in abnormal spindles in A. thaliana (Kong et al., 2010). GCP3-Interacting Protein 1 (GIP1) and GIP2 have been shown to co-localize with $\gamma$-tubulin, GCP3, and/or GCP4. In A. thaliana, reduced spindle robustness associated with lower amounts of $\gamma$-tubulin, GCP3, and GCP4 appears in the gip1 gip2 double mutants (Janski et al., 2012), implying that all these proteins may function together.

Many studies have shown that the AF cage surrounds the spindle and connects it to the cell periphery, thereby maintaining the spindle's position during mitosis (Lloyd and Traas, 1988; Katsuta et al., 1990). Recent work shows that disruption of the actin network results in misoriented spindle and oblique cell plates (Kojo et al., 2013). A number of proteins reportedly regulate the interaction between AFs and MTs involved in spindle formation and position. MAP190 from tobacco BY-2 cells cosediments with both AFs and MTs in vitro. Immunocytochemical studies revealed that MAP190 is localized in the spindle (Igarashi et al., 2000). AFH14 is also localized to spindles. T-DNA insertion mutants of AFH14 show MT abnormalities during pollen gametogenesis ( $\mathrm{Li}$ et al., 2010). Cells overexpressing AFH14 under the control of an inducible promoter increases the resistance to both MT- and AF-depolymerizing drugs, whereas AFH14 lossof-function causes alterations in MT structures and AF instability (Li et al., 2010). In Arabidopsis and BY-2 cells, AFs form a cage around spindle. Interestingly, in AFH14-overexpressing cells, the AFs and MTs co-localize in spindles (Li et al., 2010). These results suggest that proteins that interact with MTs and AFs link spindle MTs to the surrounding actin cage to regulate the spindle formation and position during mitosis.

\section{The Phragmoplast Establishment and Configuration}

Phragmoplast consists of MTs and AFs with their plus ends pointing toward the phragmoplast midzone. The phragmoplast is highly dynamic and expands toward the cell cortex to allow the cell plate growing within it to expand centrifugally. The expansion is a result of continuous MT and AF assembly at the leading edge of phragmoplast while the MTs and AFs toward the center of the phragmoplast are disassembled (Liu et al., 2011a).

A growing number of MAPs and other MT-interacting factors are associated with the phragmoplast are required for the operation of the phragmoplast (Hamada, 2007; Guo et al., 2009).
In addition to their involvement in the formation and function of the PPB and/or spindle, MOR1, CLASP, MAP65, AtKRP125c, NEDD1, and GCPs also contribute to phragmoplast establishment and configuration (Muller et al., 2004; Kawamura et al., 2006; Ambrose et al., 2007; Bannigan et al., 2007; Zeng et al., 2009; Kong et al., 2010). PAKRP1 and PAKRP1L in the kinesin12 family show high homology, and both of which localize to the midzone of the phragmoplast. Mutations at either PAKRP1 or PAKRP1L do not cause a noticeable defect. However, the phragmoplast fails to assemble normally and causes defective cell plate formation in the absence of both kinesins, thereby indicating their redundant function in the phragmoplast (Lee et al., 2007). These two kinesins are assumed to play roles in phragmoplast formation by precluding the plus ends of the opposing MT sets from crossing the midzone (Zhu and Dixit, 2012). Moreover, in the moss Physcomitrella patens, MT interdigitation in the phragmoplast depends on the kinesin KINID1, which may function as a motor for vesicle transport in the phragmoplast (Hiwatashi et al., 2008). Recently, KINID1 kinesins have also been shown to play an essential role in organizing MTs during tip growth (Hiwatashi et al., 2014). Consequently, these proteins likely contribute to the maintenance of the bipolar figure of MTs in phragmoplasts by promoting MT polymerization and/or stability. Further studies are needed to clarify the spatio-temporal and functional relationships among these proteins, which are involved in the phragmoplast.

In plant cells, $\gamma$-tubulin ring complexes ( $\gamma$-TuRCs) are capable of initiating MT nucleation at the sides of extant MTs (Murata et al., 2005). However, $\gamma$-TuRC fails to interact with the MT array directly. Consequently, protein(s) that directly interact with MTs must mediate the association of $\gamma$-TuRC with phragmoplast MTs. Plant augmin complex subunits are required for $\gamma$-tubulin recruitment, MT organization in phragmoplast, and cell plate formation (Zeng et al., 2009; Nakamura et al., 2010; Ho et al., 2011; Hotta et al., 2012). The presence of $\gamma$-tubulin in the phragmoplast MTs mainly depends on augmin because the mutation causes delocalization of $\gamma$-tubulin in the phragmoplast in augmin mutant cells of $A$. thaliana (Hotta et al., 2012). In addition, the augmin mutant phragmoplast MT array often fails to expand centrifugally, and MT bundles become disorganized (Hotta et al., 2012). In the moss $P$. patens, MT formation in phragmoplasts is severely compromised after knockdown of an augmin subunit, thereby leading to incomplete expansion of phragmoplasts (Nakaoka et al., 2012). Thus, MT-dependent MT nucleation mediated by augmin and $\gamma$-TuRC may play an important role in the organization of phragmoplast MTs.

Compared with MTs, the role of actin in the phragmoplast is less clear. Tobacco BY-2 cells treated with AF-depolymerizing drugs show disorganized phragmoplasts and wrinkled cell plates (Hoshino et al., 2003; Yoneda et al., 2004; Sano et al., 2005; Higaki et al., 2008; Kojo et al., 2013). Because arrays of AFs and MTs closely co-exist and play important roles in the phragmoplast (Smith, 1999; Yokota et al., 2009), cooperation or interaction between AFs and MTs is assumed, and several proteins have been proposed to mediate the cooperation or interaction between AFs and MTs in the cytoskeletal structure. Cotton kinesin GhKCH2, which decorates the midzone of the phragmoplast in dividing 
root tip cells, binds to AFs and MTs (Xu et al., 2009). AFH14 has been shown to localize to the phragmoplast (Li et al., 2010). Experiments in both Arabidopsis and BY-2 cells show that the length of phragmoplast MTs is longer than that of AFs. However, in AFH14-overexpressing cells, the MTs and AFs appear to be similar in length and are aligned evenly with one another ( $\mathrm{Li}$ et al., 2010). In addition to localizing to MTs and to AFs, MAP190, AtKinG, and NtKCH also localize to the phragmoplast (Igarashi et al., 2000; Buschmann et al., 2011; Klotz and Nick, 2012). Recently, in moss and tobacco, myosin VIII links phragmoplast MTs to the cortical division site via AFs during phragmoplast expansion; AFs may interact with the MTs bridging the cell cortex and the phragmoplast (Wu and Bezanilla, 2014).

\section{Conclusion and Perspectives}

Plant mitosis and cytokinesis depend on cytoskeletal dynamics. Numerous cytoskeleton-associated proteins involved in mitosis and cytokinesis have already been identified (Table 1). Based on the data in Table 1, more MAPs than actin-binding proteins have been found during the process of cell division. This may

TABLE 1 | Cytoskeleton-associated proteins involved in plant mitosis and/or cytokinesis.

\begin{tabular}{|c|c|c|c|c|}
\hline $\begin{array}{l}\text { Cytoskeleton- } \\
\text { associated } \\
\text { proteins }\end{array}$ & Proteins & Location & Function & Reference \\
\hline \multirow[t]{22}{*}{$\begin{array}{l}\text { MT-associated } \\
\text { proteins (MAPs) }\end{array}$} & MOR1/TMBP200 & PPB; spindle and phragmoplast & $\begin{array}{l}\text { Organize/stabilize } \\
\text { MTs }\end{array}$ & $\begin{array}{l}\text { Hamada et al. (2004), Kawamura et al. (2006), } \\
\text { Kawamura and Wasteneys (2008) }\end{array}$ \\
\hline & CLASP & PPB; spindle and phragmoplast & Bind to MT plus end & Ambrose et al. (2007) \\
\hline & SABRE & $\begin{array}{l}\text { Plasma membrane, } \\
\text { endomembranes, spindle, and } \\
\text { cell plate }\end{array}$ & $\begin{array}{l}\text { Stabilize } \\
\text { CLASP-labeled PPB } \\
\text { MTs }\end{array}$ & Pietra et al. (2013) \\
\hline & MAP65 & PPB and phragmoplast & Bundle MTs & Muller et al. (2004), Smertenko et al. (2004) \\
\hline & Lue1 & Cortical MTs & Sever MT & Panteris et al. (2011) \\
\hline & TON1 & PPB MTs & $\begin{array}{l}\text { Organize/stabilize } \\
\text { PPB MTs }\end{array}$ & Azimzadeh et al. (2008), Spinner et al. (2013) \\
\hline & TRM1 & Cortical MTs & Target TON1 to cortical MT & Drevensek et al. (2012), Spinner et al. (2013) \\
\hline & $\mathrm{AFH} 14$ & PPB; spindle and phragmoplast & $\begin{array}{l}\text { Bundle MTs and actin filaments } \\
\text { (AFs) and cross-link them }\end{array}$ & Li et al. (2010) \\
\hline & AtKinG & PPB and phragmoplast & Minus-end directed kinesin & Buschmann et al. (2011) \\
\hline & $\mathrm{NtKCH}$ & PPB and phragmoplast & Associate with both MTs and AFs & Klotz and Nick (2012) \\
\hline & AtKRP125c & PPB; spindle and phragmoplast & Plus-end directed kinesin & Bannigan et al. (2007) \\
\hline & $\gamma$-tubulin & Spindle and phragmoplast & $\begin{array}{l}\text { Nucleate/organize } \\
\text { MTs }\end{array}$ & Binarova et al. (2006), Pastuglia et al. (2006) \\
\hline & NEDD1 & Spindle and phragmoplast & $\begin{array}{l}\text { Nucleate/organize } \\
\text { MTs }\end{array}$ & Zeng et al. (2009) \\
\hline & GCP3 & Nuclear envelope & $\begin{array}{l}\text { Required for nuclear } \\
\text { envelope-based } \\
\text { MT nucleation }\end{array}$ & Nakamura and Hashimoto (2009) \\
\hline & GCP4 & Spindle and phragmoplast & $\begin{array}{l}\text { Nucleate/organize } \\
\text { MTs and facilitate interaction } \\
\text { between } \gamma \text {-tubulin and MTs }\end{array}$ & Kong et al. (2010) \\
\hline & GIP1, GIP2 & PPB; spindle and phragmoplast & Organize MTs & Janski et al. (2012) \\
\hline & MAP190 & Spindle and phragmoplast & Bind to and bundle MTs and AFs & Igarashi et al. (2000) \\
\hline & PAKRP1, PAKRP1L & Phragmoplast & Plus-end directed kinesin & Lee et al. (2007) \\
\hline & KINID1 & Phragmoplast & Kinesin for interdigitated MTs & Hiwatashi et al. (2008) \\
\hline & $\gamma$-TuRC & Spindle and phragmoplast & Nucleate/organize MTs & Murata et al. (2005), Zeng et al. (2009) \\
\hline & Augmin & Spindle and phragmoplast & Activate $\gamma$-TuRC & Nakaoka et al. (2012) \\
\hline & $\mathrm{GhKCH} 2$ & Phragmoplast and cell plate & $\begin{array}{l}\text { Bundle MTs and AFs and cross-link } \\
\text { them }\end{array}$ & Xu et al. (2009) \\
\hline \multirow[t]{6}{*}{$\begin{array}{l}\text { Actin-associated } \\
\text { proteins }\end{array}$} & $\mathrm{AFH} 14$ & PPB; spindle and phragmoplast & $\begin{array}{l}\text { Bundle MTs and AFs and cross-link } \\
\text { them }\end{array}$ & Li et al. (2010) \\
\hline & AtKinG & PPB and phragmoplast & Minus-end directed kinesin & Buschmann et al. (2011) \\
\hline & $\mathrm{NtKCH}$ & PPB and phragmoplast & Associate with both MTS and AFs & Klotz and Nick (2012) \\
\hline & MAP190 & Spindle and phragmoplast & Bind to and bundle MTs and AFs & Igarashi et al. (2000) \\
\hline & GhKCH2 & Phragmoplast and cell plate & $\begin{array}{l}\text { Bundle MTs and AFs and cross-link } \\
\text { them }\end{array}$ & Xu et al. (2009) \\
\hline & Myosin VIII & Spindle and phragmoplast & Actin-based molecular motors & Wu and Bezanilla (2014) \\
\hline
\end{tabular}


not imply that the role of AFs is less important than that of MTs in cell division. Because of the differences in techniques used for visualization, the sensitivity of AF to fixation, and preservation difficulty, AF observation and imaging seem to be more difficult compared with MT observation and imaging (Lloyd, 1988; Liu and Palevitz, 1992). Technological advances in microscopy imaging will facilitate the observation of AFs involved in cell division. Recent studies using confocal scanning microscopy have shown that cortical AFs are strongly correlated with mitotic spindle and phragmoplast orientations (Kojo et al., 2013, 2014). In addition, MTs and AFs are often co-distributed in the apparatus of cell division, thereby indicating that MTs and AFs may cooperate in a spatially and temporally coordinated manner through specific bifunctional proteins or multiprotein complexes. Over the past years, a growing number of proteins or protein complexes that bridge these cytoskeletal systems have been identified, including the following: MAP190, MAP18, GhKCH1,

\section{References}

Ambrose, J. C., and Cyr, R. (2008). Mitotic spindle organization by the preprophase band. Mol. Plant 1, 950-960. doi: 10.1093/mp/ssn054

Ambrose, J. C., Shoji, T., Kotzer, A. M., Pighin, J. A., and Wasteneys, G. O. (2007). The Arabidopsis CLASP gene encodes a microtubule-associated protein involved in cell expansion and division. Plant Cell 19, 2763-2775. doi: $10.1105 /$ tpc.107.053777

Azimzadeh, J., Nacry, P., Christodoulidou, A., Drevensek, S., Camilleri, C., Amiour, N., et al. (2008). Arabidopsis TONNEAU1 proteins are essential for preprophase band formation and interact with centrin. Plant Cell 20, 21462159. doi: $10.1105 /$ tpc. 107.056812

Bannigan, A., Scheible, W. R., Lukowitz, W., Fagerstrom, C., Wadsworth, P., Somerville, C., et al. (2007). A conserved role for kinesin-5 in plant mitosis. J. Cell Sci. 120, 2819-2827. doi: 10.1242/jcs.009506

Binarova, P., Cenklova, V., Prochazkova, J., Doskocilova, A., Volc, J., Vrlik, M., et al. (2006). $\gamma$-tubulin is essential for acentrosomal microtubule nucleation and coordination of late mitotic events in Arabidopsis. Plant Cell 18, 1199-1212. doi: $10.1105 /$ tpc. 105.038364

Brouhard, G. J., Stear, J. H., Noetzel, T. L., Al-Bassam, J., Kinoshita, K., Harrison, S. C., et al. (2008). XMAP215 is a processive microtubule polymerase. Cell 132, 79-88. doi: 10.1016/j.cell.2007.11.043

Buschmann, H., Green, P., Sambade, A., Doonan, J. H., and Lloyd, C. W. (2011). Cytoskeletal dynamics in interphase, mitosis and cytokinesis analysed through Agrobacterium-mediated transient transformation of tobacco BY-2 cells. New Phytol. 190, 258-267. doi: 10.1111/j.1469-8137.2010.03587.x

Chan, J., Calder, G., Fox, S., and Lloyd, C. (2005). Localization of the microtubule end binding protein EB1 reveals alternative pathways of spindle development in Arabidopsis suspension cells. Plant Cell 17, 1737-1748. doi: 10.1105/tpc.105.032615

Clayton, L., and Lloyd, C. W. (1985). Actin organization during the cell-cycle in meristematic plant cells. Actin is present in the cytokinetic phragmoplast. Exp. Cell Res.156, 231-238. doi: 10.1016/0014-4827(85)90277-0

De Mey, J., Lambert, A. M., Bajer, A. S., Moeremans, M., and De Brabander, M. (1982). Visualization of microtubules in interphase and mitotic plant cells of Haemanthus endosperm with the immuno-gold staining method. Proc. Natl. Acad. Sci. U.S.A. 79, 1898-1902. doi: 10.1073/pnas. 79.6.1898

Dixit, R., and Cyr, R. J. (2002). Spatio-temporal relationship between nuclearenvelope breakdown and preprophase band disappearance in cultured tobacco cells. Protoplasma 219, 116-121. doi: 10.1007/s007090200012

Drevensek, S., Goussot, M., Duroc, Y., Christodoulidou, A., Steyaert, S., Schaefer, E., et al. (2012). The Arabidopsis TRM1-TON1 interaction reveals a recruitment network common to plant cortical microtubule arrays
GhKCH2, OsKCH1, NtKCH, SB401, EB1, and AFH14. The mechanism underlying $\mathrm{MT}$ and $\mathrm{AF}$ cooperation or interaction remains ambiguous. To elucidate the mechanisms of MT and $\mathrm{AF}$ interaction and the regulation of these interactions, the precise function of these cross-linking proteins found and other new proteins involved in the interactions needs to be clarified and identified via proteomics and creative genetic strategies. Furthermore, technological advances in real-time imaging, such as the application of spinning disk confocal microscopy and TIRF microscopy, will potentially push forward the investigation of this issue.

\section{Acknowledgments}

This work was supported by grants from the National Natural Science Foundation of China (31130005) and the National Basic Research Program of China (2013CB126902) to Haiyun Ren.

and eukaryotic centrosomes. Plant Cell 24, 178-191. doi: 10.1105/tpc.111. 089748

Fache, V., Gaillard, J., Van Damme, D., Geelen, D., Neumann, E., StoppinMellet, V., et al. (2010). Arabidopsis kinetochore fiber-associated MAP65-4 cross-links microtubules and promotes microtubule bundle elongation. Plant Cell 22, 3804-3815. doi: 10.1105/tpc.110.080606

Guo, L., Ho, C. M., Kong, Z., Lee, Y. R., Qian, Q., and Liu, B. (2009). Evaluating the microtubule cytoskeleton and its interacting proteins in monocots by mining the rice genome. Ann. Bot. 103, 387-402. doi: 10.1093/aob/mcn248

Hamada, T. (2007). Microtubule-associated proteins in higher plants. J. Plant Res. 120, 79-98. doi: 10.1007/s10265-006-0057-9

Hamada, T., Igarashi, H., Itoh, T. J., Shimmen, T., and Sonobe, S. (2004). Characterization of a $200 \mathrm{kDa}$ microtubule-associated protein of tobacco BY2 cells, a member of the XMAP215/MOR1 family. Plant Cell Physiol. 45, 1233-1242. doi: $10.1093 / \mathrm{pcp} / \mathrm{pch} 145$

Higaki, T., Kutsuna, N., Sano, T., and Hasezawa, S. (2008). Quantitative analysis of changes in actin microfilament contribution to cell plate development in plant cytokinesis. BMC Plant Biol. 8:80. doi: 10.1186/1471-2229-8-80

Hiwatashi, Y., Obara, M., Sato, Y., Fujita, T., Murata, T., and Hasebe, M. (2008). Kinesins are indispensable for interdigitation of phragmoplast microtubules in the moss Physcomitrella patens. Plant Cell 20, 3094-3106. doi: $10.1105 /$ tpc. 108.061705

Hiwatashi, Y., Sato, Y., and Doonan, J. H. (2014). Kinesins have a dual function in organizing microtubules during both tip growth and cytokinesis in Physcomitrella patens. Plant Cell 26, 1256-1266. doi: 10.1105/tpc.113. 121723

Ho, C. M., Hotta, T., Kong, Z., Zeng, C. J., Sun, J., Lee, Y. R., et al. (2011). Augmin plays a critical role in organizing the spindle and phragmoplast microtubule arrays in Arabidopsis. Plant Cell 23, 2606-2618. doi: 10.1105/tpc.111.086892

Hoshino, H., Yoneda, A., Kumagai, F., and Hasezawa, S. (2003). Roles of actindepleted zone and preprophase band in determining the division site of higherplant cells, a tobacco BY-2 cell line expressing GFP-tubulin. Protoplasma 222, 157-165. doi: 10.1007/s00709-003-0012-8

Hotta, T., Kong, Z., Ho, C. M., Zeng, C. J., Horio, T., Fong, S., et al. (2012). Characterization of the Arabidopsis augmin complex uncovers its critical function in the assembly of the acentrosomal spindle and phragmoplast microtubule arrays. Plant Cell 24, 1494-1509. doi: 10.1105/tpc.112. 096610

Igarashi, H., Orii, H., Mori, H., Shimmen, T., and Sonobe, S. (2000). Isolation of a novel $190 \mathrm{kDa}$ protein from tobacco BY-2 cells: possible involvement in the interaction between actin filaments and microtubules. Plant Cell Physiol. 41, 920-931. doi: $10.1093 /$ pcp/pcd015

Janski, N., Masoud, K., Batzenschlager, M., Herzog, E., Evrard, J. L., Houlne, G., et al. (2012). The GCP3-interacting proteins GIP1 and GIP2 are required for 
$\gamma$-tubulin complex protein localization, spindle integrity, and chromosomal stability. Plant Cell 24, 1171-1187. doi: 10.1105/tpc.111.094904

Kakimoto, T., and Shibaoka, H. (1987). Actin-filaments and microtubules in the preprophase band and phragmoplast of tobacco cells. Protoplasma 140, 151-156. doi: 10.1007/BF01273724

Katsuta, J., Hashiguchi, Y., and Shibaoka, H. (1990). The role of the cytoskeleton in positioning of the nucleus in premitotic tobacco BY-2 cells. J. Cell Sci. 95, $413-422$.

Kawamura, E., Himmelspach, R., Rashbrooke, M. C., Whittington, A. T., Gale, K. R., Collings, D. A., et al. (2006). MICROTUBULE ORGANIZATION 1 regulates structure and function of microtubule arrays during mitosis and cytokinesis in the Arabidopsis root. Plant Physiol. 140, 102-114. doi: 10.1104/pp.105.069989

Kawamura, E., and Wasteneys, G. O. (2008). MOR1, the Arabidopsis thaliana homologue of Xenopus MAP215, promotes rapid growth and shrinkage, and suppresses the pausing of microtubules in vivo. J. Cell Sci. 121, 4114-4123. doi: $10.1242 /$ jcs. 039065

Klotz, J., and Nick, P. (2012). A novel actin-microtubule cross-linking kinesin, NtKCH, functions in cell expansion and division. New Phytol. 193, 576-589. doi: 10.1111/j.1469-8137.2011.03944.x

Kojo, K. H., Higaki, T., Kutsuna, N., Yoshida, Y., Yasuhara, H., and Hasezawa, S. (2013). Roles of cortical actin microfilament patterning in division plane orientation in plants. Plant Cell Physiol. 54, 1491-1503. doi: 10.1093/pcp/pct093

Kojo, K. H., Yasuhara, H., and Hasezawa, S. (2014). Time-sequential observation of spindle and phragmoplast orientation in BY-2 cells with altered cortical actin microfilament patterning. Plant Signal. Behav. 9 doi: 10.4161/psb.29579 [Epub ahead of print].

Kong, Z., Hotta, T., Lee, Y. R., Horio, T., and Liu, B. (2010). The $\gamma$-tubulin complex protein GCP4 is required for organizing functional microtubule arrays in Arabidopsis thaliana. Plant Cell 22, 191-204. doi: 10.1105/tpc.109. 071191

Lee, Y. R., Li, Y., and Liu, B. (2007). Two Arabidopsis phragmoplast-associated kinesins play a critical role in cytokinesis during male gametogenesis. Plant Cell 19, 2595-2605. doi: 10.1105/tpc.107.050716

Li, Y., Shen, Y., Cai, C., Zhong, C., Zhu, L., Yuan, M., et al. (2010). The type II Arabidopsis formin 14 interacts with microtubules and microfilaments to regulate cell division. Plant Cell 22, 2710-2726. doi: 10.1105/tpc.110. 075507

Liu, B., Hotta, T., Ho, M. K., and Lee, R. J. (2011a). "Microtubule organization in the phraglmoplast," in The Plant Cytoskeleton, ed. B. Liu (New York, NY: Springer), 207-225. doi: 10.1007/978-1-4419-0987-9_9

Liu, P., Qi, M., Xue, X., and Ren, H. (2011b). Dynamics and functions of the actin cytoskeleton during the plant cell cycle. Chinese Sci. Bull. 56, 3504-3510. doi: 10.1007/s11434-011-4801-8

Liu, B., and Palevitz, B. (1992). Organization of cortical microfilaments in dividing root cells. Cell Motil. Cytoskeleton 23, 252-264. doi: 10.1002/cm.970230405

Lloyd, C. W. (1988). Actin in plants. J. Cell Sci. 90, 185-188.

Lloyd, C. W., and Traas, J. A. (1988). The role of F-actin in determining the division plane of carrot suspension cells. Development 102, 211-221.

Mimori-Kiyosue, Y., Grigoriev, I., Lansbergen, G., Sasaki, H., Matsui, C., Severin, F., et al. (2005). CLASP1 and CLASP2 bind to EB1 and regulate microtubule plus-end dynamics at the cell cortex. J. Cell Biol. 168, 141-153. doi: 10.1083/jcb.200405094

Mineyuki, Y. (1999). The preprophase band of microtubules: its function as a cytokinetic apparatus in higher plants. Int. Rev. Cytol. 187, 1-49. doi: 10.1016/S0074-7696(08)62415-8

Mineyuki, Y., and Palevitz, B. A. (1990). Relationship between preprophase band organization, F-actin and the division site in Allium. J. Cell Sci. 97, 283-295.

Muller, S., Smertenko, A., Wagner, V., Heinrich, M., Hussey, P. J., and Hauser, M. T. (2004). The plant microtubule-associated protein AtMAP65-3/PLE is essential for cytokinetic phragmoplast function. Curr. Biol. 14, 412-417. doi: 10.1016/j.cub.2004.02.032

Muller, S., Wright, A. J., and Smith, L. G. (2009). Division plane control in plants: new players in the band. Trends Cell Biol. 19, 180-188. doi: 10.1016/j.tcb.2009.02.002

Murata, T., Sonobe, S., Baskin, T. I., Hyodo, S., Hasezawa, S., Nagata, T., et al. (2005). Microtubule-dependent microtubule nucleation based on recruitment of $\gamma$-tubulin in higher plants. Nat. Cell Biol. 7, 961-968. doi: 10.1038/ncb1306
Nakamura, M., and Hashimoto, T. (2009). A mutation in the Arabidopsis $\gamma$-tubulin -containing complex causes helical growth and abnormal microtubule branching. J. Cell Sci. 122, 2208-2217. doi: 10.1242/jcs. 044131

Nakamura, M., Ehrhardt, D. W., and Hashimoto, T. (2010). Microtubule and katanin-dependent dynamics of microtubule nucleation complexes in the acentrosomal Arabidopsis cortical array. Nat. Cell Biol. 12, 1064-1070. doi: $10.1038 /$ ncb2110

Nakaoka, Y., Miki, T., Fujioka, R., Uehara, R., Tomioka, A., Obuse, C., et al. (2012). An inducible RNA interference system in Physcomitrella patens reveals a dominant role of augmin in phragmoplast microtubule generation. Plant Cell 24, 1478-1493. doi: $10.1105 /$ tpc. 112.098509

Otegui, M., and Staehelin, L. A. (2000). Cytokinesis in flowering plants: more than one way to divide a cell. Curr. Opin. Plant Biol. 3, 493-502. doi: 10.1016/S13695266(00)00119-9

Palevitz, B. A. (1987). Actin in the preprophase band of Allium cepa. J. Cell Biol. 104, 1515-1519. doi: 10.1083/jcb.104.6.1515

Panteris, E., Adamakis, I. D., Voulgari, G., and Papadopoulou, G. (2011). A role for katanin in plant cell division: microtubule organization in dividing root cells of fra2 and lue1 Arabidopsis thaliana mutants. Cytoskeleton (Hoboken) 68, 401-413. doi: $10.1002 / \mathrm{cm} .20522$

Pastuglia, M., Azimzadeh, J., Goussot, M., Camilleri, C., Belcram, K., Evrard, J. L., et al. (2006). $\gamma$-tubulin is essential for microtubule organization and development in Arabidopsis. Plant Cell 18, 1412-1425. doi: 10.1105/tpc.105. 039644

Pietra, S., Gustavsson, A., Kiefer, C., Kalmbach, L., Horstedt, P., Ikeda, Y., et al. (2013). Arabidopsis SABRE and CLASP interact to stabilize cell division plane orientation and planar polarity. Nat. Commun. 4:2779. doi: $10.1038 /$ ncomms 3779

Rasmussen, C. G., Wright, A. J., and Muller, S. (2013). The role of the cytoskeleton and associated proteins in determination of the plant cell division plane. Plant J. 75, 258-269. doi: 10.1111/tpj.12177

Sabelli, P. A., and Larkins, B. A. (2009). The development of endosperm in grasses. Plant Physiol. 149, 14-26. doi: 10.1104/pp.108.129437

Sano, T., Higaki, T., Oda, Y., Hayashi, T., and Hasezawa, S. (2005). Appearance of actin microfilament 'twin peaks' in mitosis and their function in cell plate formation, as visualized in tobacco BY-2 cells expressing GFP-fimbrin. Plant J. 44, 595-605. doi: 10.1111/j.1365-313X.2005.02558.x

Smertenko, A. P., Chang, H. Y., Wagner, V., Kaloriti, D., Fenyk, S., Sonobe, S., et al. (2004). The Arabidopsis microtubule-associated protein AtMAP65-1: molecular analysis of its microtubule bundling activity. Plant Cell 16, 2035-2047. doi: 10.1105/tpc.104.023937

Smith, L. G. (1999). Divide and conquer: cytokinesis in plant cells. Curr. Opin. Plant Biol. 2, 447-453. doi: 10.1016/S1369-5266(99)00022-9

Smith, L. G. (2001). Plant cell division: building walls in the right places. Nat. Rev. Mol. Cell Biol. 2, 33-39. doi: 10.1038/35048050

Spinner, L., Gadeyne, A., Belcram, K., Goussot, M., Moison, M., Duroc, Y., et al. (2013). A protein phosphatase $2 \mathrm{~A}$ complex spatially controls plant cell division. Nat. Commun. 4:1863. doi: 10.1038/ncomms2831

Van Damme, D., Vanstraelen, M., and Geelen, D. (2007). Cortical division zone establishment in plant cells. Trends Plant Sci. 12, 458-464. doi: 10.1016/j.tplants.2007.08.011

Vanstraelen, M., Van Damme, D., De Rycke, R., Mylle, E., Inze, D., and Geelen, D. (2006). Cell cycle-dependent targeting of a kinesin at the plasma membrane demarcates the division site in plant cells. Curr. Biol. 16, 308-314. doi: 10.1016/j.cub.2005.12.035

Wasteneys, G. O., and Galway, M. E. (2003). Remodeling the cytoskeleton for growth and form: an overview with some new views. Аnnu. Rev. Plant Biol. 54, 691-722. doi: 10.1146/annurev.arplant.54.031902. 134818

Wiedemeier, A. M., Judy-March, J. E., Hocart, C. H., Wasteneys, G. O., Williamson, R. E., and Baskin, T. I. (2002). Mutant alleles of Arabidopsis RADIALLY SWOLLEN 4 and 7 reduce growth anisotropy without altering the transverse orientation of cortical microtubules or cellulose microfibrils. Development 129, 4821-4830.

Wu, S. Z., and Bezanilla, M. (2014). Myosin VIII associates with microtubule ends and together with actin plays a role in guiding plant cell division. Elife 3:e03498. doi: 10.7554/eLife.03498 
Xu, T., Qu, Z., Yang, X., Qin, X., Xiong, J., Wang, Y., et al. (2009). A cotton kinesin $\mathrm{GhKCH} 2$ interacts with both microtubules and microfilaments. Biochem. J. 421, 171-180. doi: 10.1042/BJ20082020

Yasuhara, H., and Oe, Y. (2011). TMBP200, a XMAP215 homologue of tobacco BY-2 cells, has an essential role in plant mitosis. Protoplasma 248, 493-502. doi: 10.1007/s00709-010-0189-6

Yokota, E., Ueda, S., Tamura, K., Orii, H., Uchi, S., Sonobe, S., et al. (2009). An isoform of myosin XI is responsible for the translocation of endoplasmic reticulum in tobacco cultured BY-2 cells. J. Exp. Bot. 60, 197-212. doi: 10.1093/jxb/ern280

Yoneda, A., Akatsuka, M., Hoshino, H., Kumagai, F., and Hasezawa, S. (2005). Decision of spindle poles and division plane by double preprophase bands in a BY-2 cell line expressing GFP-tubulin. Plant Cell Physiol. 46, 531-538. doi: $10.1093 / \mathrm{pcp} / \mathrm{pci055}$

Yoneda, A., Akatsuka, M., Kumagai, F., and Hasezawa, S. (2004). Disruption of actin microfilaments causes cortical microtubule disorganization and extraphragmoplast formation at M/G1 interface in synchronized tobacco cells. Plant Cell Physiol. 45, 761-769. doi: 10.1093/pcp/pch091
Zeng, C. J., Lee, Y. R., and Liu, B. (2009). The WD40 repeat protein NEDD1 functions in microtubule organization during cell division in Arabidopsis thaliana. Plant Cell 21, 1129-1140. doi: 10.1105/tpc.109.065953

Zhu, C., and Dixit, R. (2012). Functions of the Arabidopsis kinesin superfamily of microtubule-based motor proteins. Protoplasma 249, 887-899. doi: 10.1007/s00709-011-0343-9

Conflict of Interest Statement: The authors declare that the research was conducted in the absence of any commercial or financial relationships that could be construed as a potential conflict of interest.

Copyright (C) $2015 \mathrm{Li}$, Sun and Ren. This is an open-access article distributed under the terms of the Creative Commons Attribution License (CC BY). The use, distribution or reproduction in other forums is permitted, provided the original author(s) or licensor are credited and that the original publication in this journal is cited, in accordance with accepted academic practice. No use, distribution or reproduction is permitted which does not comply with these terms. 